\title{
Review and comparison of quality standards, guidelines and regulations for laboratories
}

\begin{abstract}
Authors:
Tjeerd A.M. Datema ${ }^{1}$

Linda Oskam ${ }^{1}$

Paul R. Klatser ${ }^{1,2,3}$

Affiliations:

${ }^{1}$ KIT Biomedical Research,

Royal Tropical Institute,

Amsterdam, The Netherlands

${ }^{2}$ Athena Institute, VU

University Amsterdam,

Amsterdam, The Netherlands

${ }^{3}$ Amsterdam Institute

for Global Health and

Development, Academic

Medical Centre of the

University of Amsterdam,

Amsterdam, The Netherlands

Correspondence to:

Linda Oskam

Email:

I.oskam@kit.nl

Postal address:

Meibergdreef 39, $1105 \mathrm{AZ}$

Amsterdam, The Netherlands

Dates:

Received: 26 May 2011

Accepted: 11 Nov. 2011

Published: 13 Dec. 2011

How to cite this article: Datema TAM, Oskam L, Klatser PR. Review and comparison of quality standards, guidelines and regulations for laboratories. Afr J Lab Med. 2011;1(1), Art. \#3, 7 pages. http://dx.doi. org/10.4102/ajlm.v1i1.3
\end{abstract}

(C) 2011. The Authors. Licensee: AOSIS OpenJournals. This work is licensed under the Creative Commons Attribution License.
Background: The variety and number of laboratory quality standards, guidelines and regulations (hereafter: quality documents) makes it difficult to choose the most suitable one for establishing and maintaining a laboratory quality management system.

Objectives: There is a need to compare the characteristics, suitability and applicability of quality documents in view of the increasing efforts to introduce quality management in laboratories, especially in clinical diagnostic laboratories in low income and middle income countries. This may provide valuable insights for policy makers developing national laboratory policies, and for laboratory managers and quality officers in choosing the most appropriate quality document for upgrading their laboratories.

Method: We reviewed the history of quality document development and then selected a subset based on their current use. We analysed these documents following a framework for comparison of quality documents that was adapted from the Clinical Laboratory Standards Institute guideline GP26 Quality management system model for clinical laboratory services.

Results: Differences were identified between national and international, and non-clinical and clinical quality documents. The most salient findings were the absence of provisions on occurrence management and customer service in almost all non-clinical quality documents, a low number of safety requirements aimed at protecting laboratory personnel in international quality documents and no requirements regarding ethical behaviour in almost all quality documents.

Conclusion: Each laboratory needs to investigate whether national regulatory standards are present. These are preferred as they most closely suit the needs of laboratories in the country. A laboratory should always use both a standard and a guideline: a standard sums up the requirements to a quality management system, a guideline describes how quality management can be integrated in the laboratory processes.

\section{Introduction}

After the development of the plan-do-check-act cycle by Deming (based on the work of Shewart) in the $1920 \mathrm{~s}, 1,2$ the principles of quality management (QM) spread and became especially important in private industry. QM has many advantages, including protecting the product quality, customer safety and the company's reputation. Requirements for regulation of processes are recorded in documents called 'standards'. National and international quality standards were developed by several organisations. Simultaneously, governments forced the introduction of QM by means of laws and regulatory standards.

In laboratory practice the necessity of QM also became apparent, although later than in industry. Laboratory quality standards first focused only on testing laboratories and calibration laboratories, with the first international standard (ISO Guide 25) launched in 1978 by the International Organization for Standardization (ISO). Nowadays, many national and international quality standards for laboratory practice exist and quality laboratory practice has become the norm. In the case of full compliance with standard requirements a laboratory may be accredited: a formal recognition of competence and compliance to a quality standard.

Documents other than standards are important as well. Quality standards are lists of requirements that need to be met in order to ensure quality practice. These standards do not contain explanations on how to implement the requirements or comply with them. In addition, standards are mostly not measurable. Therefore, a laboratory needs guidelines describing how to implement the standard requirements and a checklist to visualise the degree to which it has met the standard. 
Since 2008 the initiatives to strengthen laboratories in low and middle income countries (LMIC) have evolved rapidly, especially in the clinical diagnostic laboratory sector. ${ }^{3}$ Whilst efforts to increase health in LMIC initially focused on improving treatment and care, the focus has now broadened to also improving laboratory diagnosis. Stakeholders encourage countries to develop national standards, guidelines and regulations (hereafter called 'quality documents') to improve the quality of laboratory testing, contributing to meeting the Millennium Development Goals (MDG) to achieve better health. ${ }^{4,5,6}$ In 2009 the World Health Organization (WHO) regional office for Africa (WHO-AFRO) launched an accreditation checklist based on international quality documents $5,7,8,9,10,11$ and in 2005 the WHO regional office for South East Asia (WHO-SEARO) recommended the expansion of the national accreditation scheme of Thailand to member countries. ${ }^{2,12}$

The number of international laboratory quality documents is large and their scopes are diverse. As a result, deciding which document to use for implementing QM may be difficult: the authors have observed clinical laboratories implementing quality standards meant for non-clinical laboratories. This points to a lack of knowledge of decision makers regarding the existence of different types of quality documents for different types of laboratories. No review of widely used laboratory quality documents has been published to describe their characteristics and differences. We believe that there is a need for such information in the context of the rapidly increasing efforts to introduce QM in clinical laboratories. Here we review documents that are widely used in QM implementation in laboratories, followed by an analysis of selected documents.

The target audience of this study is the clinical laboratory sector. However, non-clinical laboratory quality documents were also included to provide perspective by showing their differences when compared with clinical laboratory quality documents (explaining why they should not be used by clinical laboratories). This analysis is intended for policy makers developing national laboratory quality policies, and for laboratory managers and staff with the ambition to implement a quality management system (QMS).

\section{Methodology \\ Selection of laboratory quality documents}

Laboratory QM development was reviewed using an unstructured Internet search to identify quality documents that are internationally important and widely used. Of these, seven quality documents were selected for further study five international standards or guidelines and two national US regulations.

ISO 17025 - General requirements for test and calibration laboratories was included because it was the first internationally published standard (in 1978) on laboratory QM, originally named ISO Guide 25. ${ }^{13}$ This standard is presently widely used for testing and calibration laboratories.
In 1979 in the USA, the Food and Drug Administration (FDA) enacted a national regulation called Good Laboratory Practice for Nonclinical Laboratory Studies (21CFR58) (hereafter called FDA-GLP). ${ }^{14,15}$ In 1981 the Organization for Economic Cooperation and Development (OECD) translated the FDA-GLP into international requirements for testing and calibration laboratories in its member states, titled Principles on Good Laboratory Practice (OECD-GLP), consisting of a series of documents focusing on the different aspects of accreditation. ${ }^{16}$ The OECD-GLP could be regarded as the second quality document to ever be developed specifically for international use.

In 1988 a national regulation made expressly for clinical laboratories was enacted in the USA. This regulation is known as Clinical Laboratory Improvement Amendments (CLIA), coded 42CFR493. ${ }^{17}$ The CLIA is a national regulation, but the College of American Pathologists (CAP) uses it as the basis for its accreditation ${ }^{18}$ that is provided to clinical laboratories worldwide. Therefore, the CLIA is also of international significance.

ISO 15189 - Medical Laboratories - Particular requirements for quality and competence is the most widely used clinical laboratory standard. It was published for the first time in 2003. ${ }^{19}$ The version used in our analysis is from 2007.

In 1999 the Clinical and Laboratory Standards Institute (CLSI) developed GP26-A1, a guideline for establishing a QMS in clinical laboratories. The development of the guideline started in 1997 by combining all the requirements of six quality documents (current at that time) into one document. ${ }^{20}$ In 2006 the ISO 15189 requirements were incorporated into the third edition of this guideline (GP26-A3) titled: Application of a Quality Management System Model for Laboratory Services; Approved Guideline. ${ }^{21}$ In the spring of 2011 the fourth edition was published (GP26-A4). This guideline is used internationally to implement the requirements of ISO 15189 in clinical laboratories.

The Joint Commission International (JCI) Accreditation standard for clinical laboratories (second edition published in 2010) has a rather different background from the other quality standards included in this study. The JCI provides accreditation to hospitals. As part of this accreditation, the JCI developed the standard to include QM practices in hospital laboratories. ${ }^{22}$ Because JCI hospital accreditation is widespread, the significance of JCI laboratory accreditation may also increase (Table 1 provides an overview of the selected quality documents for analysis, including background information).

\section{Analysis of quality documents}

To guide the analysis, a framework was constructed consisting of three steps to analyse the selected quality documents. In step 1 the nature of the quality document was determined. We used the following definitions:

- International standard: a consensus document developed for international use, summing up all the requirements for a QMS. 
- International guideline: a more descriptive document than a standard, developed for international use, defining the intent of standard requirements and how these should be integrated in the laboratory processes.

- National regulation: regulatory standard written by a national government.

In step 2 a framework of 12 Quality System Essentials (QSEs) was adapted from the CLSI guideline for implementing QM in clinical laboratories: GP26-A3. ${ }^{21}$ These 12 QSEs together cover all aspects of a QMS (Figure 1). When analysing the selected quality documents, their articles or sub-parts were allocated to one of the 12 QSEs to yield an indication of the level of coverage of total quality by each quality document (Table 2). Finally, in step 3 additional characteristics of each quality document were recorded.

\section{Results}

The results of the analysis of the nature of the quality documents (analysis step 1) are provided (Table 1). The FDAGLP, developed for non-clinical research laboratories, and the CLIA, developed for clinical diagnostic laboratories, are both national regulatory standards. The quality documents developed for international use included the OECD-GLP, ISO 17025:2005, ISO 15189:2007, CLSI GP26-A3 and the JCI clinical laboratory standard, 2nd edition. The OECD-GLP and ISO 17025 were developed for use in non-clinical laboratories and the ISO 15189, CLSI GP26 and JCI clinical laboratory standard were developed for use in clinical laboratories.

The results of determining the level of coverage of total quality by each quality document (analysis step 2) are provided (Table 2).

\section{Clinical quality documents}

In general, customers play an important role in clinical laboratory quality documents. Whereas the non-clinical quality documents are generally written from the perspective of protecting the process and its product, the clinical quality documents are written to protect the customer from flawed results.

The attention given to continuous improvement is much higher in clinical quality documents than in non-clinical quality documents. Also, occurrence management (correct handling of nonconformities/accidents, followed by improvement measures to prevent similar occurrences in the future) receives much more attention in clinical quality documents than in non-clinical quality documents.

\section{ISO 15189}

Of all clinical laboratory quality documents studied, ISO 15189 is probably the most widely used standard worldwide. Regional and international accreditation organisations such as the International Laboratory Accreditation Cooperation (ILAC), the InterAmerican Accreditation Cooperation (IAAC), the Asia Pacific Laboratory Accreditation Cooperation (APLAC) and the European Cooperation for Accreditation (EA) recommend accreditation of clinical laboratories to ISO $15189 .{ }^{23}$

A notable characteristic of the ISO 15189 standard is, besides the requirements to a QMS, the inclusion of two annexes with recommendations: one contains all recommendations for a laboratory information system and another is completely dedicated to different aspects of ethics. ${ }^{24}$

\section{CLSI GP26}

As a standard, ISO 15189 is a document that only contains requirements for a QMS, but no further explanation on why and how these requirements should be complied with. The CLSI GP26 guideline contains much more information for laboratories on what QM is, how it is integrated in the laboratory work, and why certain activities should be performed. The CLSI GP26 approaches every laboratory

TABLE 1: Overview of analysed quality documents with their most important characteristics.

\begin{tabular}{|c|c|c|c|c|c|c|}
\hline Name & Category $\dagger$ & $\begin{array}{l}\text { National or } \\
\text { international: }\end{array}$ & Type of document $\S$ & $\begin{array}{l}\text { Developed or } \\
\text { maintained by }\end{array}$ & First publication $\dagger \dagger$ & $\begin{array}{l}\text { Used publication } \\
\text { or editiontt }\end{array}$ \\
\hline $\begin{array}{l}\text { ISO } 17025 \text { General requirements for } \\
\text { the competence of testing and } \\
\text { calibration laboratories }\end{array}$ & Non-clinical & International & $\begin{array}{l}\text { International } \\
\text { standard }\end{array}$ & ISO & $\begin{array}{l}\text { 1999 (Guide } \\
\text { 25: 1978) }\end{array}$ & 2005/2nd edition \\
\hline $\begin{array}{l}\text { Good Laboratory Practice for } \\
\text { Non-clinical Laboratory Studies }\end{array}$ & Non-clinical & National (USA) & $\begin{array}{l}\text { National regulation } \\
\text { (USA) }\end{array}$ & FDA & 1978 & $\begin{array}{l}2009 \text { (revision } \\
\text { April 1) }\end{array}$ \\
\hline $\begin{array}{l}\text { Principles on Good Laboratory } \\
\text { ractice }\end{array}$ & Non-clinical & International & $\begin{array}{l}\text { International } \\
\text { standard }\end{array}$ & OECD & 1981 & 1998/1st revision \\
\hline $\begin{array}{l}\text { Clinical Laboratory Improvement } \\
\text { Amendments }\end{array}$ & Clinical & National (USA) & $\begin{array}{l}\text { National regulation } \\
\text { (USA) }\end{array}$ & US Government & 1988 & $\begin{array}{l}2004 \text { (revision } \\
\text { January 24) }\end{array}$ \\
\hline $\begin{array}{l}\text { ISO } 15189 \text { Medical Laboratories - } \\
\text { Particular requirements for quality } \\
\text { and competence }\end{array}$ & Clinical & International & $\begin{array}{l}\text { International } \\
\text { standard }\end{array}$ & ISO & 2003/1st edition & 2007/2nd edition \\
\hline $\begin{array}{l}\text { CLSI GP26 Application of a quality } \\
\text { management system model for } \\
\text { laboratory service }\end{array}$ & Clinical & International & $\begin{array}{l}\text { International } \\
\text { guideline }\end{array}$ & CLSI & 1999/A1 & 2004/A3 \\
\hline $\begin{array}{l}\mathrm{JCl} \text { Accreditation Standards for } \\
\text { Clinical Laboratories }\end{array}$ & Clinical & International & $\begin{array}{l}\text { International } \\
\text { standard and } \\
\text { guideline in one }\end{array}$ & $\mathrm{JCl}$ & 2003/1st edition & 2010/2nd edition \\
\hline
\end{tabular}

$\dagger$, The type of laboratory for which the quality document was developed: either clinical diagnostic laboratories or non-clinical testing or calibration laboratories.

$\$$, The focus area for use of the quality document: either national or international use.

$\S$, The type of document: an international standard, an international guideline or a national regulation (regulatory standard), with the name of the country it was developed by between brackets.

q, The organisation that developed the quality document.

T, The organisation that developed the quality

$1 \dagger$, The date the first edition was published.
$4 \mathrm{t}$, The date and edition used for analysis. 


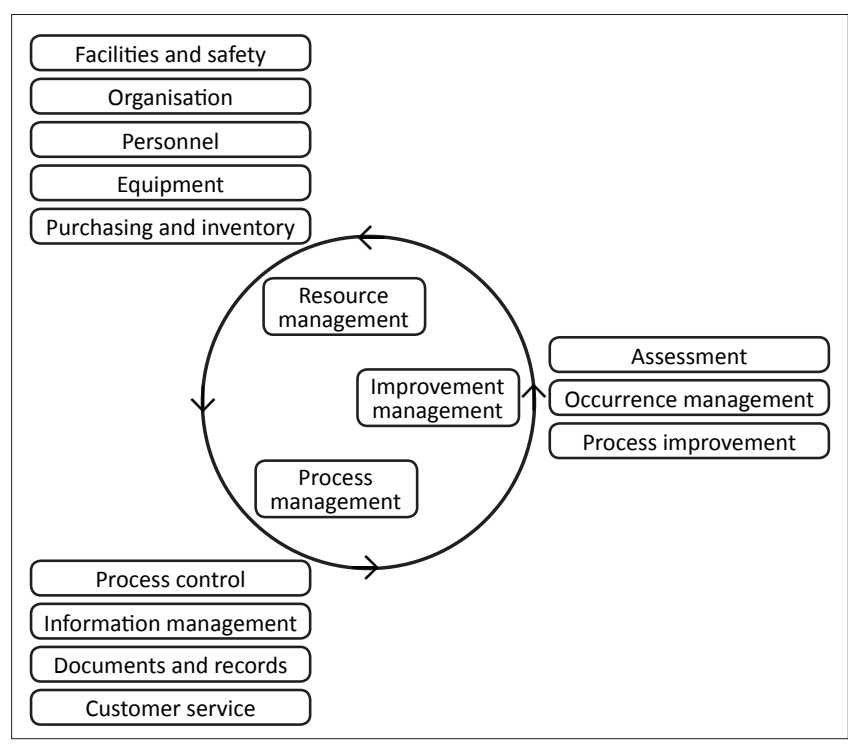

The 12 QSEs are allocated to the different stages of the quality cycle. This cycle represents the continuous improvement cycle that should be present in all processes of a quality mancent system. It consists of a resource manement al presses of a quality management system. It consists of a resource management stage, a process management stage and an improvement management stage. The Deming cycle, also known as the PDCA cycle (Plan, Do, Check and Act cycle), can be identified in the quality cycle; planning with resource management, 'doing' in the process management, and checking every activity and upon identification of nonconformities, acting with preventive, concurrent and corrective actions in the improvement management stage.

FIGURE 1: The framework with the 12 Quality System Essentials used to analyse to which extent the content of quality documents covers all aspects of total quality management.

activity from a process workflow perspective. It contains a detailed description of this workflow by discussing each phase of the process using flow charts and process tables. The remainder of the document describes the requirements per QSE, which are highly focused on continuous improvement (when compared to other clinical laboratory quality documents).

\section{The Clinical Laboratory Improvement Amendments}

The CLIA is a US federal document that applies to all clinical laboratory testing performed on humans except for clinical trials and fundamental research. This regulation is comprehensive and contains many discipline specific requirements (i.e. special requirements for histopathology, genetic testing, molecular techniques, etc.). Remarkably, the nature of the CLIA is more similar to non-clinical quality documents as it is primarily focused on protecting the analysis process rather than customers and personnel. However, the CLIA, in contrast to most non-clinical standards, covers all 12 QSEs, which indicates that it is specifically designed for clinical laboratory practice.

\section{JCI Clinical Laboratory Standard}

The JCI accreditation standard is slightly different from the aforementioned standards as it is a highly elaborate document that combines a standard with a guideline, describing the intent of each standard requirement and, uniquely, the measurable elements of each requirement. It is most elaborate on safety requirements, but it is the only clinical laboratory document which does not cover all 12 QSEs: information management is not covered as a topic in itself, although some requirements related to information management are present as part of different sections in the document. This standard is, similarly to the CLIA, highly elaborate on sub disciplines within laboratory practice providing quality assurance and quality control standards for each specific discipline.

\section{Non-clinical quality documents}

The most salient findings are that the non-clinical quality documents are less customer focused and, instead, written from the perspective of protecting the process and its product.

Non-clinical quality documents are also less focused on continuous improvement; both the FDA-GLP and OECDGLP lack requirement on this QSE. In addition, the FDA-GLP also lacks requirements on the purchasing and inventory element of the QMS.

Another salient characteristic of most non-clinical quality documents (FDA-GLP, OECD-GLP, and ISO 17025) is the requirement to have a study plan or validated protocol in place besides Standard Operating Procedures (SOPs).

\section{Discussion}

There are a number of quality documents specific for clinical laboratories and for non-clinical laboratories. We compared the characteristics, suitability and applicability of these quality documents in view of the increasing efforts to introduce QM in laboratories. Clinical quality documents focus on both protecting the process, and the safety of the customer and the laboratory staff, whereas non-clinical documents aim primarily at protecting the safety and integrity of the analyses performed. Moreover, non-clinical quality documents are generally not focused on continuous improvement, an aspect that could be regarded as one of the major goals of a QMS.

\section{Clinical laboratory quality documents}

The fact that ISO 15189 includes a complete annex on ethics is exceptional when compared to all other quality documents. In clinical laboratory practice patient confidentiality and proper behaviour towards the patient are obvious ethical requirements. However, regulations regarding financial arrangements of the laboratory staff with external organisations or persons, or protection of the environment through correct waste-management are also ethical requirements. Therefore, we recommend including a paragraph containing specific ethical norms with regard to laboratory practice in every quality document.

It was observed that the CLIA is highly comprehensive when compared to other clinical quality documents. This may be related to the fact that the CLIA is adapted to a national situation (with laboratories in the USA generally having abundant resources to facilitate good quality practice), whilst ISO 15189, as an international standard, has to maintain a certain level of generality to make it applicable in multiple countries that may have different standards of practice that are often determined by resource availability. 
TABLE 2a: Analysis of contents of national quality documents using the Quality System Essentials framework.

\begin{tabular}{|c|c|c|}
\hline \multirow{3}{*}{ Quality System Element (QSE) } & \multicolumn{2}{|c|}{ National quality documents } \\
\hline & Non-clinical & Clinical \\
\hline & FDA GLP for non-clinical testing & CLIA \\
\hline Facilities and safety & Sub-part C: 58.41 / 58.43 / 58.45 / 58.47 / 58.49 / 58.51 & Sub-part J: 493.1100-493.1101 \\
\hline Organisation & Sub-part B: 58.31 / 58.33 / 58.35 & $\begin{array}{c}\text { Sub-part K: } 493.1200-.1239 \text { / } 493.1242-.1249 \text { / } 493.1282 \text { / } 493.1289 \text { / } \\
493.1299\end{array}$ \\
\hline Personnel & Sub-part B: 58.29 & Sub-part M: 493.1351-.1495 \\
\hline Equipment & Sub-part D: 58.61 / 58.63 & Sub-part K: 493.1252-.1255 \\
\hline Purchasing and inventory & $x$ & Sub-part K: 493.1252 \\
\hline Process control & $\begin{array}{c}\text { Sub-part E: } 58.81 \text { / } 58.83 \text { / } 58.90 \text { / Sub-part F: } 58.105 \text { / } 58.113 \text { / } \\
\text { Sub-part G: } 58.120 \text { / 58.130a-d }\end{array}$ & $\begin{array}{c}\text { Sub-part K: } 493.1232 \text { / } 493.1240-.1242 \text { / } 493.1250-.1251 \text { / } 493.1256- \\
.1282 \text { / } 493.1290\end{array}$ \\
\hline Information management & Sub-part G: 58.130 e / Sub-part J: 58.185 & Sub-part K: 493.1231 / 493.1291 \\
\hline Documents and records & Sub-part J: $58.190 / 58.195$ & $\begin{array}{l}\text { Sub-part J: } 493.1101 \mathrm{e} / 493.1105 / \\
\text { Sub-part K: } 493.1283\end{array}$ \\
\hline Customer service & $\mathrm{x}$ & $\begin{array}{c}\text { Sub-part K: 493.1233-.1234 / 493.1291e / Sub-part M: } 493.1407 \text { / } \\
493.1419\end{array}$ \\
\hline Assessment & $\begin{array}{c}\text { Sub-part K: } 58.200 / 58.202 / 58.204 / 58.206 / 58.210 / 58.213 / \\
58.215 / 58.217 / 58.219\end{array}$ & $\begin{array}{c}\text { Sub-part H: } 493.801-.807 \text { / Sub-part K: } 493.1239 \text { / } 493.1249 \text { / } \\
\text { 493.1253-.1254 / 493.1289 / } 493.1299\end{array}$ \\
\hline Occurrence management & $x$ & Sub-part K: 493.1233-.1234 / 493.1282 \\
\hline Process improvement & $\mathrm{x}$ & Sub-part K: 493.1236-.1239 / 493.1249 / 493.1289 / 493.1299 \\
\hline
\end{tabular}

A dash (-) indicates a separation (e.g. chapter 1-3: chapters 1 till 3), a slash (/) indicates a sum (e.g. chapter 1/ 3: chapters 1 and 3).

$X$, indicates no contents of the quality document to the related QSE.

TABLE 2b: Analysis of contents of international quality documents using the Quality System Essentials framework.

\begin{tabular}{|c|c|c|c|c|c|}
\hline \multirow[t]{3}{*}{ Quality System Element (QSE) } & \multicolumn{5}{|c|}{ International quality documents } \\
\hline & \multicolumn{2}{|c|}{ Non-clinical } & \multicolumn{3}{|c|}{ Clinical } \\
\hline & OECD Principles on GLP & ISO 17025:2005 & ISO 15189:2007 & CLSI GP26-A3 & $\begin{array}{l}\mathrm{JCl} \text { clinical laboratory } \\
\text { standard }\end{array}$ \\
\hline Facilities and safety & 3 & 5.3 & 5.2 / B2 & 6.12 & $\begin{array}{c}\text { MGT.4.7-.4.9 / RSM.3-.3.2.1 } \\
\text { / RSM.5-.7.3 }\end{array}$ \\
\hline Organisation & $\begin{array}{c}1.1 .1 / 1.1 .2 \mathrm{a} / 1.1 .2 \mathrm{e}-\mathrm{q} / \\
1.2 / 2.2\end{array}$ & $4.1 / 4.2 / 5.1$ & $4.1 / 4.2$ & 6.2 & $\begin{array}{c}\text { MGT.1-.1.1 / MGT.1.3-.2.2 / } \\
\text { MGT.4-.4.1.3 }\end{array}$ \\
\hline Personnel & $1.1 .2 \mathrm{~b}-\mathrm{c}$ & 5.2 & 5.1 & 6.3 & RSM.1-.2 \\
\hline Equipment & $4 / 5$ & 5.5 & 5.3 / B1 / B7 / B8 & 6.4 & RSM.1 / RSM.4-.4.3 \\
\hline Purchasing and inventory & $\begin{array}{l}\text { (guidelines provided } \\
\text { separately) }\end{array}$ & $4.4 / 4.5 / 4.6$ & $4.4 / 4.5 / 4.6$ & 6.5 & $\begin{array}{c}\text { MGT.1.2-.1.2.2 / RSM.1 / } \\
\text { RSM.4.4-.4.5 }\end{array}$ \\
\hline Process control & $6 / 7$ / 8.1.1-8.3.2 & $5.4 / 5.6 / 5.7 / 5.8 / 5.9$ & $\begin{array}{c}5.4 / 5.5 / 5.6 / 5.7 / 5.8 / C 4 \\
\text { / C5 / C6 / C9 }\end{array}$ & 6.6 & $\begin{array}{c}\text { MGT.4.2-.4.6 / DCP.2-.5 / } \\
\text { QCP.1-.14.6 }\end{array}$ \\
\hline Information management & 8.3.3-8.3.5 / 9 & 5.10 & $\begin{array}{c}5.8 / \mathrm{B} 4 / \mathrm{B} 5 / \mathrm{B} 6 / \mathrm{C} 3 / \mathrm{C} 4 \\
/ \mathrm{C} 6 / \mathrm{C} 8\end{array}$ & 6.7 & $\mathrm{x}$ \\
\hline Documents and records & 10 & $4.3 / 4.13$ & $4.3 / 4.13 / C 7 / C 8$ & 6.1 & DCP.1 / DCP.5 \\
\hline Customer service & $x$ & $4.2 .4 / 4.7 / 4.8$ & $4.7 / 4.8$ & 6.11 & MGT.3-.3.2 \\
\hline Assessment & $\begin{array}{l}\text { (guidelines provided } \\
\text { separately) }\end{array}$ & $4.14 / 4.15$ & $4.14 / 4.15 / 5.6 .4$ & 6.9 & MGT.4.1.4 / MGT.4.10 \\
\hline Occurrence management & $x$ & $4.9 / 4.11 / 4.12$ & $4.9 / 4.10 / 4.11$ & 6.8 & DCP.4.3 / QCP.1.7 \\
\hline Process improvement & $\mathrm{x}$ & 4.10 & 4.12 & 6.10 & MGT.4-.4.1.6 / MGT.4.7-.4.9 \\
\hline
\end{tabular}

A dash (-) indicates a separation (e.g. chapter 1-3: chapters 1 till 3), a slash (/) indicates a sum (e.g. chapter 1/ 3: chapters 1 and 3).

$X$, indicates no contents of the quality document to the related QSE.

The CLIA is more focused on protecting the process rather than the customers and personnel, making it different compared to other clinical quality documents. This may be a typical characteristic of a regulation that can have a narrower focus because other national regulations cover, for example, occupational safety (e.g. the USA 29 CFR part $1910{ }^{25}$ ): clinical laboratories in the USA following the CLIA need to comply with multiple other national regulations, whereas international standards and guidelines have to provide complete sets of requirements covering all aspects of laboratory practice.

\section{Non-clinical laboratory quality documents}

Most non-clinical laboratory quality documents are primarily process-focused. This may be the reason for the total absence of personnel safety requirements: the paragraphs of non-clinical quality documents shown in Table 2 in the QSE Facilities and Safety are all related to proper facilities and actions enabling safety of the process, not directed at the safety of personnel. This is illustrated by the requirement of the FDA-GLP in sub-part B, 58.29 (d): 'personnel shall take necessary personal sanitation and health precautions designed to avoid contamination of test and control articles and test systems'.

A characteristic found to be specific for non-clinical quality documents is the requirement to have a study plan or validated protocol in place besides SOPs. Often, nonclinical laboratories perform research in addition to routine procedures. This research cannot be standardised in SOPs.

Notable, and probably related to the nature of test and calibration laboratories, is the low number of requirements 
aiming at the QSE Process Improvement. In clinical laboratories, processes consist mainly of routinely performed procedures. Continuous improvement is necessary to keep the performance of these procedures as efficient and effective as possible. In calibration laboratories, techniques should be performed with as little variance as possible, whereas variation in activities is inherent to the work of testing laboratories. Incorporating continuous improvement is therefore complicated, if not impossible.

QSEs that are left uncovered in all but one of the nonclinical quality documents are Occurrence Management and Customer Service. Establishing procedures on customer service and occurrence management may be advisable in any environment. Only ISO 17025 contains requirements related to both QSEs, probably due to the incorporation of the highly customer-focused ISO 9001 standard during its development. ${ }^{13,26}$

\section{National versus international laboratory quality documents}

In many countries, international quality documents serve as the basis for national quality documents. Such adaption leads to documents that vary by country with regard to comprehensiveness. For example, the national guideline for clinical laboratories in the Netherlands is more extensive than the ISO 15189 standard. ${ }^{27}$ The same applies to the USA CLIA and FDA-GLP regulations. In contrast, the Chinese standard is less extensive than the ISO 15189, which makes it more feasible for laboratories in China to attain the standard. ${ }^{28}$ The required level of ISO 15189 was considered to be too high in relation to the resources available, with the consequence that few laboratories in China tried to become accredited. By making the national standards easier to achieve, Chinese laboratories were encouraged to implement QM leading to a substantial increase in accredited laboratories. ${ }^{28}$ On one hand some efforts on QM are better than no efforts at all, the concern however is the question in how far such simplified national standards can maintain adequate quality. This should be a topic of further research.

Nevertheless, it is recommended to use national quality regulations, if available, as they are often more detailed and optimally adapted to the national situation, and take into account the available resources. The problem is that national standards are currently almost exclusively available in highincome countries. In the last decade, several middle-income countries, for example Thailand, Mexico and Argentina, have developed simplified national accreditation schemes based on international standards. . $9,30,31,32$ Recently, WHO-AFRO together with, among others, the USA Centers for Disease Control and Prevention (CDC) has launched an accreditation checklist based on CLSI GP26 and ISO 15189, which is tailormade for implementation in clinical laboratories in LMIC, and has started the roll-out in sub-Saharan Africa. ${ }^{7}$ A strong point is that the absence of national regulations is taken into account in this initiative: the WHO-AFRO accreditation checklist contains lots of questions regarding laboratory safety that would otherwise need to be covered by national regulations on occupational safety..$^{11}$ ISO 15189 only refers to national or regional regulations for safety requirements in such instances; these are absent in many countries.

\section{Study limitations}

A potential weakness of this study is that the framework for analysis was adapted from a clinical laboratory quality document. This means that this framework was tailor-made for clinical laboratory quality documents and thus biased towards a clinical laboratory QMS. Although we therefore were able to correctly identify gaps in non-clinical quality documents compared to clinical quality documents, we were not able to identify gaps in clinical laboratory quality documents as compared to non-clinical quality documents.

\section{Recommendations}

The type of laboratory and the resources available determine which document suits the practice of the laboratory best. National regulations are generally more detailed and tailor-made to the national laboratory system. International guidelines may be less detailed in order to remain applicable in multiple countries.

Laboratories planning to establish a QMS need both a standard and a guideline. A standard provides no information on the reasons for implementation of the requirements, and standards are generally not measurable. The JCI document illustrates the need for more than a standard: in this document the requirements (standard) are supplemented with a description of the intent of the requirements to prevent misinterpretation (guideline). In addition, measurable elements help the laboratory to determine whether each requirement is complied with.

It is important that documents are chosen which suit the practice of a laboratory best. Hence, clinical laboratories should choose a clinical laboratory standard, not the FDAGLP, OECD-GLP, ISO 17025 or any other non-clinical laboratory document.

Several suggestions and recommendations remain to developers of quality documents. It was observed that non-clinical quality documents generally lack provisions on occurrence management, customer service and process improvement; we recommend including requirements on these aspects. Ethics is also an element that applies to all types of organisations. Increasing attention to ethical behaviour is highly recommended.

\section{Acknowledgements}

We would like to thank Mirjam Engelberts for useful suggestions.

\section{Competing interests}

The authors declare that they have no financial or personal relationship(s), which may have inappropriately influenced them in writing this article. 


\section{Authors' contributions}

T.A.M.D. (Royal Tropical Institute) Datema was involved in designing the study, analysing the documents and writing of the article. L.O. (Royal Tropical Institute) was involved in designing and supervising the study and writing of the article. P.R.K. (Royal Tropical Institute) was involved in designing the study and writing of the article.

\section{References}

1. The W. Edwards Deming Institute [homepage on the Internet]. c2011 [cited 2011 Nov 11]. Available from: http://deming.org/index.cfm?content $=61$

2. Western Electric History [homepage on the Internet]. c2011 [cited 2011 Nov 11]. Available from: http://www.porticus.org/bell/westernelectric_history. html\#Western\%20Electric\%20-\%20A\%20Brief\%20History

3. World Health Organization. Joint WHO-CDC conference on health laboratory quality systems; 2008 Apr 09-11; Lyon, France. Report no.: WHO/HSE/IHR/ LYO/2008.3. Available from: http://www.who.int/ihr/lyon/report20080409.pdf

4. United Nations General Assembly. United Nations millennium declaration; 2000 Sept 08; New York City, USA. Resolution no.: A/res/55/2. Available from: http:// www.un.org/millennium/declaration/ares552e.pdf

5. World Health Organization Regional Office for Africa. The Maputo declaration on strengthening of laboratory systems; 2008 Jan 24; Maputo, Mozambique. Available from: http://www.who.int/diagnostics_laboratory/Maputo-Declaration 2008.pdf

6. United Nations. Millennium development goals [homepage on the Internet] c2010 [cited 2011 Nov 11]. Available from: http://www.un.org/millenniumgoals

7. Gershy-Damet GM, Rotz P, Cross D, et al. The World Health Organization African region laboratory accreditation process: Improving the quality of laboratory systems in the African region. Am J Clin Pathol. 2010;134(3):393-400. http:// systems in the African region. Am J Clin Pathol. 2010;134(3)
dx.doi.org/10.1309/AJCPTUUC2V1WJQBM, PMid:20716795

8. Nkengasong JN, Nsubuga $P$, Nwanyanwu $O$, et al. Laboratory systems and services are critical in global health: Time to end the neglect? Am J Clin Pathol. 2010;134(3):368-373. http://dx.doi.org/10.1309/AJCPMPSINQ9BRMU6, PMid:20716791

9. Yao K, McKinney B, Murphy A, et al. Improving quality management systems of laboratories in developing countries: An innovative training approach to accelerate laboratory accreditation. Am J Clin Pathol. 2010;134(3):401-409. http://dx.doi.org/10.1309/AJCPNBBL53FWUIQJ, PMid:20716796

10. Regional Committee. Strengthening public health laboratories in the WHO African region: A critical need for disease control; 2008 Sept 02; Yaounde, Cameroon. Resolution no.: AFR/RC58/R2.

11. Datema TAM, Oskam L, Van Beers SM, Klatser PK. Critical review of the stepwise laboratory improvement process towards accreditation: Suggestions for harmonization, implementation and improvement. Trop Med Int Health. http:// dx.doi.org/10.1111/j.1365-3156.2011.02917.x, PMid:22093245

12. Kusum M, Silva P. Quality standards in health laboratories - Implementation in Thailand: A novel approach. World Health Organization regional office for SouthEast Asia; 2005. Report no.: SEA-HLM-386 ed.
13. International Organization for Standardization. ISO 17025 General requirements for test and calibration laboratories. Geneva: ISO; 2005.

14. Food and Drug Administration. 21 CFR58 Good laboratory practice for non-clinical laboratory studies. USA: Food and Drug Administration; 1978.

15. Food and Drug Administration. History of the FDA [homepage on the Internet]. c2011 [updated 2010 Jul 29; cited 2011 Nov 11]. Available from: http://www.fda. gov/AboutFDA/WhatWeDo/History/default.htm

16. Organization for Economic Co-operation and Development. Principles on good laboratory practice. Paris, France: Organization for Economic Co-operation and Development; 1998.

17. Center for Medicare and Medicaid Services (US). Clinical laboratory improvement amendments [homepage on the Internet]. c2011 [cited 2011 Nov 11]. Available from: http://www.access.gpo.gov/nara/cfr/waisidx_04/42cfr493_04.html

18. Scully TA. Continuance of the approval of the College of American Pathologists as a CLIA accreditation organization. Federal Register, Vol 66, no 177, 2001

19. International Organization for Standardization. ISO 15189 Medical laboratories Particular requirements for quality and competence. Geneva: ISO; 2003.

20. Berte LM. Laboratory quality management: a roadmap. Clin Lab Med. 2007;27(4):771-790. http://dx.doi.org/10.1016/j.cll.2007.07.008, PMid:17950897

21. Clinical Laboratory Standards Institute. Application of a quality management system model for laboratory services, approved guideline GP26-A3. 3rd ed. Wayne, Pennsylvania: NCCLS; 2004.

22. Joint Commission International. Accreditation standards for clinical laboratories. 2nd ed. Oakbrook Terrace Illinois; Joint Commision International: 2010.

23. ILAC-Members (by category). International Laboratory Accreditation Cooperation [homepage on the Internet]. c2011 [cited 2011 Nov 03]. Available from: http:// www.ilac.org/membersbycategory.html

24. International Organization for Standardization. ISO 15189 Medical laboratories Particular requirements for quality and competence. Geneva: ISO; 2007.

25. Occupational Safety and Health Administration. United States Department of Labor [homepage on the Internet]. c2011 [cited 2011 Nov 11]. Available from: http://www.osha.gov/index.html

26. International Organization for Standardization. ISO 9001 Quality management systems - Requirements. Geneva: ISO; 2008.

27. [Foundation to promote the quality of the laboratory and the accreditation of laboratories in health care (CCKL). Fourth practical guideline for a quality system for a laboratory in the health care system]. 4th ed. Bilthoven, the Netherlands: CCKL; 2005. Dutch.

28. Yang Zh. The laboratory accreditation and regulations of clinical laboratory in China. Clin Biochem. 2009;42:310. http://dx.doi.org/10.1016/j.clinbiochem.2008.09.027, PMid:19863937

29. Mazziotta D. Accreditation of clinical laboratories in the Latin-American region. Clin Biochem. 2009;42:309. http://dx.doi.org/10.1016/j.clinbiochem.2008.09.026, PMid:19863936

30. Sierra-Amor RI, López-Martinez M. Medical laboratory accreditation according to ISO 15189:2003. The Mexican experience. Biochem Med. 2007;17(2):188-192.

31. Sierra-Amor RI. Mexican experience on laboratory accreditation according to ISO 15189:2003. Clin Biochem. 2009;42:318. http://dx.doi.org/10.1016/j. clinbiochem.2008.09.095, PMid:19863944

32. Wattanasri N, Manoroma W, Viriyayudhagorn S. Laboratory accreditation in Thailand: A systemic approach. Am J Clin Pathol. 2010;134(4):534-540. http:// dx.doi.org/10.1309/AJCPZYY19WMKMAZT, PMid:20855633 